\title{
Cefoxitin disc diffusion test for detection of meticillin-resistant staphylococci
}

\author{
Correspondence \\ Amita Jain \\ amita602002@yahoo.com
}

Received 6 January 2007

Accepted 4 April 2008

\author{
Amita Jain, Astha Agarwal and Raj Kumar Verma \\ Department of Microbiology, King George's Medical University, Lucknow, UP, 226003, India
}

\section{INTRODUCTION}

In recent years, an increase in the number of meticillinresistant (MR) Staphylococcus aureus and MR coagulasenegative staphylococci (CoNS) strains has become a serious clinical and epidemiological problem, as resistance to this antibiotic implies resistance to all $\beta$-lactam antibiotics. Accuracy and promptness in the detection of meticillin resistance are of key importance in ensuring correct antibiotic treatment in infected patients and control of MR staphylococci in the hospital environment (Velasco et al., 2005). MR staphylococci have also emerged as a frequent cause of community-acquired infections (Naimi et al., 2003).

There are several phenotypic methods, such as MIC determination [by agar dilution $(\mathrm{AD})$, broth dilution and E-test], the oxacillin screen agar (OSA) method and disc diffusion (DD) testing, for detection of MR staphylococci. Phenotypic expression of resistance can vary depending on the growth conditions (e.g. temperature, osmolarity and

Abbreviations: AD, agar dilution; CoNS, coagulase-negative staphylococci; DD, disc diffusion; MR, meticillin-resistant; OSA, oxacillin screen agar; PBP2a, penicillin-binding protein 2a. culture medium supplements such as $\mathrm{NaCl}$ or sucrose) (Ferreira et al., 2003; Sakoulas et al., 2001), making susceptibility testing by standard microbiological methods potentially problematic.

The mecA gene is highly conserved in staphylococcal strains and thus is a useful marker of meticillin/oxacillin resistance (Ferreira et al., 2003). Its detection is considered the gold standard for detection of MR isolates. However, many laboratories throughout the world do not have the capacity to use molecular techniques to detect MR staphylococci in routine clinical practice.

Susceptibility to oxacillin by disc diffusion has been used for the detection of MR staphylococcal strains in routine testing; however, some recent studies have reported low sensitivity and low specificity of oxacillin compared with cefoxitin for the detection of MR isolates (Palazzo \& Darini, 2006; Swenson \& Tenover, 2005). The aim of this study was to evaluate the accuracy of a cefoxitin DD test and other phenotypic methods for the detection of oxacillin resistance in staphylococci compared with detecting the presence of the mecA gene for routine detection of MR staphylococci. 


\section{METHODS}

Clinical isolates. We tested 144 clinical isolates of staphylococci: 97 S. aureus and 47 CoNS. These isolates were recovered from blood (11 S. aureus and 14 CoNS), peripheral intravenous devices (26 S. aureus and eight CoNS), skin swabs collected from the site of peripheral intravenous device insertion (20 S. aureus and nine CoNS) and anterior nasal fossa (40 S. aureus and $16 \mathrm{CoNS}$ ) referred to the Department of Microbiology from the Department of Pediatrics, Chhatrapati Sahuji Maharaj Medical University, India. Isolates were collected over a period of 1 year from January to December 2005 and identified to species level using standard methods (Kloos \& Bannerman, 1999; Monsen et al., 1998).

Antimicrobial susceptibility testing. Susceptibility to oxacillin and cefoxitin was determined by the DD method on Mueller-Hinton agar plates (Hi-Media Laboratories) using a bacterial suspension with the turbidity adjusted to a $0.5 \mathrm{McF}$ arland standard. Plates were incubated at $35{ }^{\circ} \mathrm{C}$ for $24 \mathrm{~h}$. Results were interpreted according to CLSI (2005) guidelines. The interpretive criteria for cefoxitin were: $S$. aureus, sensitive $\geqslant 20 \mu \mathrm{g} \mathrm{ml}^{-1}$, resistant $\leqslant 19 \mu \mathrm{g} \mathrm{ml}^{-1}$; CoNS, sensitive $\geqslant 25 \mu \mathrm{g} \mathrm{ml}^{-1}$, resistant $\leqslant 24 \mu \mathrm{g} \mathrm{ml}^{-1}$. The interpretive criteria for oxacillin were: $S$. aureus, sensitive $\geqslant 13 \mu \mathrm{g} \mathrm{ml}^{-1}$, resistant $\leqslant 12 \mu \mathrm{g}$ $\mathrm{ml}^{-1}$; CoNS, sensitive $\geqslant 18 \mu \mathrm{g} \mathrm{ml}^{-1}$, resistant $\leqslant 17 \mu \mathrm{g} \mathrm{ml}^{-1}$.

OSA test. All plates were prepared with Mueller-Hinton agar supplemented with $4 \%(\mathrm{w} / \mathrm{v}) \mathrm{NaCl}$ containing oxacillin. Two types of plate were prepared, one containing oxacillin at a concentration of $4 \mu \mathrm{g} \mathrm{ml}^{-1}$ (OSA $4 \mu \mathrm{g} \mathrm{ml}^{-1}$ ) and another containing oxacillin at a concentration of $6 \mu \mathrm{g} \mathrm{ml}^{-1}$ (OSA $6 \mu \mathrm{g} \mathrm{m}^{-1}$ ). All plates were spot inoculated with a cotton swab dipped into a 0.5 McFarland standard suspension of each isolate, according to the procedures outlined by the CLSI (2005). Oxacillin resistance was confirmed by bacterial growth after $24 \mathrm{~h}$ incubation at $35{ }^{\circ} \mathrm{C}$.

Agar dilution test. The MIC for oxacillin was determined by an $\mathrm{AD}$ method, following CLSI guidelines. Briefly, for each isolate, a minimum of four to five colonies isolated from an overnight growth were transferred to sterile saline. The suspension was adjusted to a 0.5 McFarland standard $\left(10^{8}\right.$ c.f.u. $\left.\mathrm{ml}^{-1}\right)$ and spot inoculated on Mueller-Hinton agar plates supplemented with $2 \% \mathrm{NaCl}$ and containing 256-0.125 $\mu \mathrm{g}$ oxacillin $\mathrm{ml}^{-1}$ in serial doubling dilutions. The oxacillin Mueller-Hinton plates were incubated at $35{ }^{\circ} \mathrm{C}$ for $24 \mathrm{~h}$. The oxacillin susceptibility breakpoint currently recommended by the CLSI for the $\mathrm{AD}$ testing method is $\leqslant 2 \mu \mathrm{g} \mathrm{ml} l^{-1}$ for $S$. aureus and $\leqslant 0.5 \mu \mathrm{g} \mathrm{ml}^{-1}$ for CoNS.

Detection of the mecA gene. Four to five colonies of an overnight bacterial subculture were suspended in $100 \mu$ lysis buffer [10 mM Tris/HCl ( $\mathrm{pH} 8.0$ ), 2 mM EDTA, $0.4 \% \mathrm{NaCl}, 0.1 \%$ Triton X-100], vortexed for $5 \mathrm{~min}$ and boiled for $15 \mathrm{~min}$ followed by centrifugation at 3000 r.p.m. for $10 \mathrm{~min}$ at room temperature. The supernatant was used for DNA amplification. The forward (5'-CATTTTGAGTTCTGCACTACC-3') and reverse (5'-GCAATACAATCGCACATACATTAATAG-3') primers (Ryffel et al., 1992) were synthesized by Bangalore Genie, India. The reaction mixture $(20 \mu \mathrm{l}$ total $)$ containing $2 \mu \mathrm{l}$ extracted DNA, $10 \mathrm{mM}$ Tris/ $\mathrm{HCl}$ ( $\mathrm{pH} 8.0$ ), $50 \mathrm{mM} \mathrm{KCl}, 1.5 \mathrm{mM}$ $\mathrm{MgCl}_{2}, 200 \mu \mathrm{M}$ each dNTP, $1.0 \mathrm{U}$ Taq DNA polymerase and $100 \mathrm{pM}$ each primer was used to PCR amplify the mecA gene in an automated thermal cycler (Progene/Techne). The amplified product of $967 \mathrm{bp}$ was detected by ethidium bromide staining following $1.5 \%$ agarose gel electrophoresis (Jaffe et al., 2000).

\section{RESULTS AND DISCUSSION}

Detection of the mecA gene was positive in 73/97 S. aureus $(75.26 \%)$ and $30 / 47$ CoNS (63.83\%) isolates. Table 1 shows the results for the phenotypic methods used for detection of meticillin resistance in the present study. The cefoxitin DD test could detect meticillin resistance only in 68/73 mecA-positive $S$. aureus and 24/25 mecA-positive CoNS. mecA-negative S. aureus (23/24) and CoNS (17/17) were accurately detected by the cefoxitin DD test. The use

Table 1. Detection of oxacillin resistance in S. aureus and CoNS

The results are shown as the number of resistant isolates. The interpretative criteria used in the susceptibility tests are defined in Methods

\begin{tabular}{|c|c|c|c|c|c|}
\hline Strain (no. of isolates) & OSA $4 \mu \mathrm{g} \mathrm{ml}^{-1}$ & OSA $6 \mu \mathrm{g} \mathrm{ml}^{-1}$ & AD & Oxacillin DD & Cefoxitin DD \\
\hline mecA-positive S. aureus (73) & 73 & 72 & 72 & 73 & 68 \\
\hline mecA-negative S. aureus (24) & 10 & 9 & 1 & 10 & 1 \\
\hline mecA-positive CoNS (30) & 25 & 22 & 25 & 26 & 24 \\
\hline mecA-negative CoNS (17) & 2 & 1 & 1 & 5 & 0 \\
\hline
\end{tabular}

Table 2. Statistical analysis of phenotypic methods used for the detection of MR in staphylococci

PPV, positive predictive value; NPV, negative predictive value.

\begin{tabular}{|c|c|c|c|c|c|c|c|c|}
\hline \multirow[t]{2}{*}{ Method } & \multicolumn{2}{|c|}{ Sensitivity (\%) } & \multicolumn{2}{|c|}{ Specificity (\%) } & \multicolumn{2}{|c|}{ PPV (\%) } & \multicolumn{2}{|c|}{ NPV (\%) } \\
\hline & S. aureus & CoNS & S. aureus & CoNS & S. aureus & CoNS & S. aureus & CoNS \\
\hline OSA $4 \mu \mathrm{g} \mathrm{ml}^{-1}$ & 100.00 & 83.33 & 58.33 & 88.24 & 87.95 & 92.59 & 100.00 & 75.00 \\
\hline OSA $6 \mu \mathrm{g} \mathrm{ml}^{-1}$ & 98.63 & 73.33 & 62.50 & 94.12 & 88.89 & 95.65 & 93.75 & 66.67 \\
\hline $\mathrm{AD}$ & 98.63 & 83.33 & 98.53 & 94.12 & 98.63 & 96.15 & 95.83 & 76.19 \\
\hline Oxacillin DD & 100.00 & 86.67 & 58.33 & 70.59 & 87.95 & 83.87 & 100.00 & 75.00 \\
\hline Cefoxitin DD & 94.44 & 80.00 & 95.83 & 100.00 & 98.55 & 100.00 & 82.14 & 73.91 \\
\hline
\end{tabular}


of oxacillin in the DD test and in the OSA $4 \mu \mathrm{g} \mathrm{ml}^{-1}$ and OSA $6 \mu \mathrm{g} \mathrm{ml}^{-1}$ tests was more sensitive but less specific than the cefoxitin DD test (Tables 1 and 2). The results of the oxacillin $\mathrm{AD}$ test were comparable to those of the mecA PCR (Tables 1 and 2). The sensitivity and specificity of each method are shown in Table 2. The cefoxitin DD test was less sensitive than the oxacillin DD test but was more specific for both S. aureus and CoNS.

Determination of the oxacillin MIC is a method recommended by the CLSI for the detection of meticillin resistance. As shown in Table 3, we found one mecA-positive S. aureus strain with an MIC less than the cut-off value of $2 \mu \mathrm{g} \mathrm{ml}^{-1}$ and one mecA-negative S. aureus strain with an MIC greater than the cut-off value. A large number of mecA-positive CoNS isolates (5/30) demonstrated an MIC less than or equal to the cut-off point of $0.5 \mu \mathrm{g} \mathrm{ml}^{-1}$, and one mecA-negative CoNS isolate had an MIC greater than the cut-off point.

The discrepant results for S. aureus and CoNS are shown in Tables 4 and 5, respectively. The most important discrepancy was encountered in 8/24 mecA-negative (meticillinsensitive) S. aureus isolates, which demonstrated oxacillin resistance by the majority of phenotypic methods except for the cefoxitin DD test and the AD method.

In the present study, it was found that the cefoxitin DD test was more specific and less sensitive than the OSA method

Table 3. Oxacillin MIC for $m e c A$-positive and $m e c A$-negative $S$. aureus and CoNS

Numbers in bold indicate discrepant results. The interpretative criteria used are defined in Methods.

\begin{tabular}{|c|c|c|c|c|c|c|c|c|c|c|c|c|}
\hline Strain (no. of isolates) & \multicolumn{12}{|c|}{$\operatorname{MIC}\left(\mu \mathrm{g} \mathrm{ml}^{-1}\right)$} \\
\hline mecA-negative $S$. aureus (24) & 2 & 7 & 7 & 5 & 2 & & 1 & & & & & \\
\hline mecA-positive CoNS (30) & & 2 & 3 & & & 3 & 2 & 2 & 2 & 1 & 5 & 10 \\
\hline mecA-negative CoNS (17) & 2 & 5 & 9 & & & & 1 & & & & & \\
\hline
\end{tabular}

Table 4. Discrepant results for $S$. aureus isolates

R, Resistant; S, sensitive.

\begin{tabular}{|c|c|c|c|c|c|c|}
\hline Strain & No. of isolates & OSA $4 \mu \mathrm{g} \mathrm{ml}^{-1}$ & OSA $6 \mu \mathrm{g} \mathrm{ml}^{-1}$ & $\mathrm{AD}$ & Oxacillin DD & Cefoxitin DD \\
\hline mecA-positive & 1 & $\mathrm{R}$ & $\mathrm{R}$ & S & $\mathrm{R}$ & S \\
\hline \multirow[t]{3}{*}{$m e c A$-negative } & 1 & $\mathrm{R}$ & $\mathrm{R}$ & $\mathrm{R}$ & $\mathrm{R}$ & $\mathrm{R}$ \\
\hline & 8 & $\mathrm{R}$ & $\mathrm{R}$ & $\mathrm{S}$ & $\mathrm{R}$ & S \\
\hline & 1 & S & S & S & $\mathrm{R}$ & S \\
\hline
\end{tabular}

Table 5. Discrepant results for CoNS

R, Resistant; S, susceptible.

\begin{tabular}{|c|c|c|c|c|c|c|}
\hline Strain & No. of isolates & OSA $4 \mu \mathrm{g} \mathrm{ml}^{-1}$ & OSA $6 \mu \mathrm{g} \mathrm{ml}^{-1}$ & $\mathrm{AD}$ & Oxacillin DD & Cefoxitin DD \\
\hline \multirow[t]{5}{*}{$m e c A$-positive } & 2 & S & $S$ & S & $S$ & S \\
\hline & 2 & $S$ & $S$ & S & $\mathrm{R}$ & S \\
\hline & 1 & $S$ & S & $\mathrm{S}$ & $S$ & $\mathrm{R}$ \\
\hline & 1 & $\mathrm{R}$ & $\mathrm{R}$ & $\mathrm{R}$ & S & S \\
\hline & 3 & $\mathrm{R}$ & $S$ & $\mathrm{R}$ & $\mathrm{R}$ & $\mathrm{R}$ \\
\hline \multirow{2}{*}{$m e c A$-negative } & 1 & $\mathrm{R}$ & $\mathrm{R}$ & $\mathrm{R}$ & $\mathrm{R}$ & S \\
\hline & 3 & $\mathrm{~S}$ & $\mathrm{~S}$ & $\mathrm{~S}$ & $\mathrm{R}$ & S \\
\hline
\end{tabular}


and the oxacillin DD test for both CoNS and S. aureus, and that it was comparable with MIC determination (AD test) and the mecA PCR. Overall, the accuracy of the cefoxitin DD test was better than that of the oxacillin DD test for the detection of MR staphylococci. It also does not require special testing conditions such as a lower incubation temperature $\left(35^{\circ} \mathrm{C}\right)$ and $\mathrm{NaCl}$ supplementation in the testing media, as required by the oxacillin DD test. According to previously reported studies, the sensitivity and specificity of the cefoxitin DD test for $S$. aureus has been reported to be $95-100 \%$ and $98-100 \%$, respectively (Flayhart et al., 2005; Skov et al., 2003; Swenson \& Tenover, 2005; Velasco et al., 2005). The reported sensitivity and specificity for CoNS is $92.5-99 \%$ and $98.6-96 \%$, respectively (Palazzo \& Darini, 2006; Swenson \& Tenover, 2005). Cefoxitin is considered to be a better predictor than oxacillin for the detection of heteroresistance because it is a stronger inducer of penicillin-binding protein 2a (PBP2a) (Cauwelier et al., 2004; Felten et al., 2002).

The reported sensitivity and specificity of the oxacillin DD test for S. aureus is $90.4-98 \%$ and $83-99 \%$, respectively (Boutiba-Ben Boubaker et al., 2004a; Kircher et al., 2004). Use of the oxacillin DD test for the detection of MR staphylococci was less specific compared with the cefoxitin DD test, as also reported by Palazzo \& Darini (2006). It has been reported that oxacillin resistance among staphylococci is caused by expression of PBP2a encoded by the $m e c A$ gene, which has a low binding affinity to all $\beta$-lactam antibiotics available in clinical practice (Boutiba-Ben Boubaker et al., 2004b; Cauwelier et al., 2004; Skov et al., 2003). Detection of oxacillin resistance is complicated because different populations of staphylococci express different levels of resistance.

The reported sensitivity and specificity of the AD method are $94.4-100 \%$ and $85-100 \%$, respectively, for S. aureus (Flayhart et al., 2005; Sakoulas et al., 2001; Swenson \& Tenover, 2005). For CoNS, the reported sensitivity and specificity are $81-100 \%$ and $73.5-97.4 \%$, respectively (DeGiusti et al., 1999; Ferreira et al., 2003; Palazzo \& Darini, 2006; Swenson \& Tenover, 2005). The discrepancies obtained in our study were also reported by Geha et al. (1994), who maintained that such discrepancies occur due to hyperproduction of $\beta$-lactamase. Gerberding et al. (1991) reported a specific group of MR isolates, called BORSA (borderline oxacillin-resistant $S$. aureus). These strains were characterized by a meticillin MIC at or just above the susceptibility breakpoint. Borderline strains may be divided into two categories on the basis of whether $m e c A$ is present or not. Borderline strains that contain $m e c A$ are extremely heterogeneous MR strains that produce PBP2a. These strains have resistant subpopulations of cells, although these may be quite small, that can grow at high drug concentrations (Gerberding et al., 1991). Borderline strains that do not contain mecA can be differentiated phenotypically from extremely heterogeneous mecA-positive strains. Borderline resistance in $m e c A$-negative strains has been hypothesized to result from modification of the normal PBP gene or overproduction of staphylococcal $\beta$ lactamase (McDougal \& Thornsberry, 1986; Tomasz et al., 1989).

Previous studies have reported the sensitivity and specificity of the OSA test to be $94.3-100 \%$ and $83-100 \%$, respectively (Kircher et al., 2004; Sakoulas et al., 2001; Velasco et al., 2005). According to Ferreira et al. (2003), the sensitivity and specificity of the OSA test were 99.7 and $100 \%$, respectively, at a concentration of $4 \mu \mathrm{g} \mathrm{ml}^{-1}$, and 75.7 and $100 \%$, respectively, at a concentration of $6 \mu \mathrm{g} \mathrm{ml}^{-1}$.

We conclude that the oxacillin DD test is more sensitive but less specific than the cefoxitin DD test. For accurate screening of MR staphylococci, both cefoxitin and oxacillin discs should be included in the DD test. For confirmation of meticillin resistance, especially in oxacillin-resistant and cefoxitin-sensitive strains, the oxacillin $\mathrm{AD}$ test is a reliable method and is comparable to mecA PCR.

\section{REFERENCES}

Boutiba-Ben Boubaker, I., Ben Abbes, R., Ben Abdallah, H., Mamlouk, K., Mahjoubi, F., Kammoun, A., Hammami, A. \& Ben, R. S. (2004a). Evaluation of a cefoxitin disk diffusion test for the routine detection of methicillin-resistant Staphylococcus aureus. Clin Microbiol Infect 10, 762-765.

Boutiba-Ben Boubaker, I., Ben Abbes, R., Ben Abdallah, H., Mamlouk, K., Mahjoubi, F., Kammoun, A., Hammami, A. \& Ben Redjeb, S. (2004b). Evaluation of a cefoxitin disk diffusion test for the routine detection of methicillin-resistant Staphylococcus aureus. Clin Microbiol Infect 10, 762-765.

Cauwelier, B., Gordts, B., Descheemaecker, P. \& Van Landuyt, H. (2004). Evaluation of a disk diffusion method with cefoxitin $(30 \mu \mathrm{g})$ for detection of methicillin-resistant Staphylococcus aureus. Eur J Clin Microbiol Infect Dis 23, 389-392.

CLSI (2005). Performance Standards for Antimicrobial Susceptibility Testing, 15th Informational Supplement M100-S15. Wayne, PA: Clinical Laboratory Standards Institute.

De Giusti, M., Pacifico, L., Tufi, D., Panero, A., Boccia, A. \& Chiesa, C. (1999). Phenotypic detection of nosocomial mecA-positive coagulasenegative staphylococci from neonates. J Antimicrob Chemother 44, 351-358.

Felten, A., Grandry, B., Lagrange, P. H. \& Casin, I. (2002). Evaluation of three techniques for detection of low-level methicillin-resistant Staphylococcus aureus (MRSA): a disk diffusion method with cefoxitin and moxalactam, the Vitek 2 system, and the MRSA-screen latex agglutination test. J Clin Microbiol 40, 2766-2771.

Ferreira, R. B., lorio, N. L., Malvar, K. L., Nunes, A. P., Fonseca, L. S., Bastos, C. C. \& Santos, K. R. (2003). Coagulase-negative staphylococci: comparison of phenotypic and genotypic oxacillin susceptibility tests and evaluation of the agar-screening test by using different concentrations of oxacillin. J Clin Microbiol 41, 3609-3614.

Flayhart, D., Hindler, J. F., Bruckner, D. A., Hall, G., Shrestha, R. K., Vogel, S. A., Richter, S. S., Howard, W., Walther, R. \& Carroll, K. C. (2005). Multicenter evaluation of BBL CHROMagar MRSA medium for direct detection of methicillin-resistant Staphylococcus aureus from surveillance cultures of the anterior nares. J Clin Microbiol 43, 5536-5540.

Geha, D. J., Uhl, J. R., Gustaferro, C. A. \& Persing, D. H. (1994). Multiplex PCR for identification of methicillin-resistant staphylococci in the clinical laboratory. J Clin Microbiol 32, 1768-1772. 
Gerberding, J. L., Miick, C., Liu, H. H. \& Chambers, H. F. (1991) Comparison of conventional susceptibility tests with direct detection of penicillin-binding protein $2 \mathrm{a}$ in borderline oxacillin-resistant strains of Staphylococcus aureus. Antimicrob Agents Chemother 35, 2574-2579.

Jaffe, R. I., Lane, J. D., Albury, S. V. \& Niemeyer, D. M. (2000). Rapid extraction from and direct identification in clinical samples of methicillin-resistant staphylococci using the PCR. J Clin Microbiol 38, 3407-3412.

Kircher, S., Dick, N., Ritter, V. \& Sturm, K. (2004). Detection of methicillin-resistant Staphylococcus aureus using a new medium, $\mathrm{BBL}^{\mathrm{TM}}$ CHROMagar ${ }^{\mathrm{TM}}$ MRSA, compared to current methods. Presented at the 104th General Meeting of the American Society for Microbiology, New Orleans, LA. American Society for Microbiology.

Kloos, W. E. \& Bannerman, T. L. (1999). Staphylococcus and Micrococcus. In Manual of Clinical Microbiology, 7th edn, pp. 264282. Edited by P. R. Murry, E. J. Baron, M. Pfaller, A. F. C. Tenover \& R. K. Yolken. Washington, DC: American Society for Microbiology.

McDougal, L. K. \& Thornsberry, C. (1986). The role of $\beta$-lactamase in staphylococcal resistance to penicillinase-resistant penicillins and cephalosporins. J Clin Microbiol 23, 832-839.

Monsen, T., Rönnmark, M., Olofsson, C. \& Wiström, J. (1998). An inexpensive and reliable method for routine identification of staphylococcal species. Eur J Clin Microbiol Infect Dis 17, 327-335.

Naimi, T. S., LeDell, K. H., Como-Sabetti, K., Borchardt, S. M., Boxrud, D. J., Etienne, J., Johnson, S. K., Vandenesch, F., Fridkin, S. $\&$ other authors (2003). Comparison of community- and health careassociated methicillin-resistant Staphylococcus aureus infection. JAMA 290, 2976-2984.
Palazzo, I. C. \& Darini, A. L. (2006). Evaluation of methods for detecting oxacillin resistance in coagulase-negative staphylococci including cefoxitin disc diffusion. FEMS Microbiol Lett 257, 299-305.

Ryffel, C., Kayser, F. H. \& Berger-Bächi, B. (1992). Correlation between regulation of mecA transcription and expression of methicillin resistance in staphylococci. Antimicrob Agents Chemother $36,25-31$.

Sakoulas, G., Gold, H. S., Venkataraman, L., DeGirolami, P. C., Eliopoulos, G. M. \& Qian, Q. (2001). Methicillin-resistant Staphylococcus aureus: comparison of susceptibility testing methods and analysis of mecA-positive susceptible strains. J Clin Microbiol 39, 3946-3951.

Skov, R., Smyth, R., Clausen, M., Larsen, A. R., Frimodt-Møller, N., Olsson-Liljequist, B. \& Kahlmeter, G. (2003). Evaluation of a cefoxitin $30 \mu \mathrm{g}$ disc on Iso-Sensitest agar for detection of methicillin-resistant Staphylococcus aureus. J Antimicrob Chemother 52, 204-207.

Swenson, J. M. \& Tenover, F. C. (2005). Cefoxitin Disk Study Group. Results of disk diffusion testing with cefoxitin correlate with presence of mecA in Staphylococcus spp. J Clin Microbiol 43, 3818-3823.

Tomasz, A., Drugeon, H. B., de Lencastre, H. M., Jabes, D., McDougall, L. \& Bille, J. (1989). New mechanism for methicillin resistance in Staphylococcus aureus: clinical isolates that lack the PBP $2 \mathrm{a}$ gene and contain normal penicillin-binding proteins with modified penicillin-binding capacity. Antimicrob Agents Chemother 33, 1869-1874.

Velasco, D., del Mar Tomas, M., Cartelle, M., Beceiro, A., Perez, A., Molina, F., Moure, R., Villanueva, R. \& Bou, G. (2005). Evaluation of different methods for detecting methicillin (oxacillin) resistance in Staphylococcus aureus. J Antimicrob Chemother 55, 379-382. 